\title{
Investigating the Performances of a Coated Plain Weave Fabric Designed for Producing Protective Gowns
}

\author{
Imene Ghezal $\mathbb{D}^{1,2}{ }^{1,2}$ Boubaker Jaouachi, ${ }^{1,2}$ and Faouzi Sakli ${ }^{1,3}$ \\ ${ }^{1}$ Textile Engineering Laboratory (LR 11ES42), University of Monastir, 5070 Ksar-Hellal, Tunisia \\ ${ }^{2}$ National Engineering School of Monastir, University of Monastir, 5019 Monastir, Tunisia \\ ${ }^{3}$ Higher Institute of Technological Studies of Ksar-Hellal, 5070 Ksar-Hellal, Tunisia \\ Correspondence should be addressed to Imene Ghezal; elghezalimene@hotmail.com
}

Received 12 April 2021; Revised 7 October 2021; Accepted 8 October 2021; Published 26 October 2021

Academic Editor: Gianfranco Carotenuto

Copyright (c) 2021 Imene Ghezal et al. This is an open access article distributed under the Creative Commons Attribution License, which permits unrestricted use, distribution, and reproduction in any medium, provided the original work is properly cited.

The aim of this research is to produce a substrate that can be used for the development of protective gowns. For this purpose, a cottonpolyester blended plain weave fabric was treated with a coating paste comprising fluorocarbon and acrylic resins. The coating process parameters, which are fluorocarbon resin quantity (\%), acrylic paste quantity $\left(\mathrm{g} \mathrm{m}^{-2}\right)$, and reticulation time (min), were varied by using a Box-Behnken experimental design. Textile fabric characteristics in terms of thickness $(\mathrm{mm})$, coating add-on (\%), air permeability $\left(\mathrm{L} \mathrm{m}^{-2} \mathrm{~s}^{-1}\right)$, surface hydrophobicity $(\mathrm{mg} \mathrm{cm})$, and flexural rigidity $\left(\mathrm{mg} \mathrm{cm}^{-1}\right)$ were then analyzed and discussed.

\section{Introduction}

The coronavirus crisis is spreading all over the globe causing daily high mortality rates. Since the beginning of the pandemic and up to February 23rd, 2021, the World Health Organization (WHO) reported 2.474 .112 deaths in the world. The world's economic situation was also affected by the pandemic [1]. Scientists are trying to find out manners to stop the virus spreading. They are focusing on developing vaccines. When it comes to the textile field, researchers are producing garments with a blocking-transmission effect [2]. New functional textiles such as protective gowns and barrier masks are gaining interest [3]. Protective gowns are under the personal protective equipment (PPE) category [3]. They are used to protect healthcare providers and patients from potential surrounded hazard or also to avoid a field contamination by infected individuals [3-5].

Protective gowns can be either disposable (single-use gowns) or reusable (multiuse gowns) $[4,6]$. Single-use gowns are formed with nonwoven fabrics that are made with synthetic fibers. These nonwovens can be either laminated or not with polymeric films [6, 7]. To produce multiuse gowns, tightly woven plain weave fabrics, generally obtained with cotton, polyester, or cotton/polyester blends, are coated with chemical finishing. The substrate is then used for designing reusable gowns $[4,6]$.

The purpose of this research was the development of a coated textile that can be used for producing protective gowns. Towards that end, a cotton-polyester (cotton-PES) blended woven fabric was coated by using the screen coating technique. The applied coating contains fluorocarbon (Fluorotex FO/57) and acrylic resins (Setaprint PTL). In previous works that were done by Ghezal et al. $[8,9]$, a cotton-PES double-sided knit was coated with acrylic and fluorocarbon polymers. The substrate was found to be breathable with enhanced hydrophobic properties. In this research, the assessment of mixing acrylic and fluorocarbon polymers was also used. The effects of both used resins and the reticulation time on the woven fabric final performances were analyzed by using the Minitab 18 software. Thickness $(\mathrm{mm})$, coating add-on (\%), optical microscopy analysis, infrared spectroscopy analysis, air permeability $\left(\mathrm{L} \mathrm{m}^{-2} \mathrm{~s}^{-1}\right)$, 
water repellency, and flexural rigidity $(\mathrm{mg} \mathrm{cm})$ were measured before and after the coating treatment of the blended woven fabric.

\section{Materials and Methods}

2.1. Textile Material and Chemical Reagents. To produce the substrate for designing protective gowns, a woven cottonpolyester fabric was supplied from the Tunisian textile market. Furthermore, the applied coating paste is a resin mixture comprising fluorocarbon and acrylic dispersions. Indeed, the fluorocarbon resin, namely, Fluorotex FO/ $57 \mathrm{~W}$, is a nonionic-slightly cationic dispersion. The acrylic resin, namely, Setaprint PTL, has an anionic character. Both product preparations contain crosslinking agents. These products were supplied from CHIMITEX, Tunisia.

2.2. Coating Process. To apply an even polymeric layer to the woven fabric, the screen printing process was used. In fact, the used screen physical characteristics are recapitulated in Table 1.

By using the Box-Behnken experimental design, input parameters were varied according to fifteen experimental sets. Fluorocarbon resin quantity (\%), acrylic paste quantity $\left(\mathrm{g} \mathrm{m}^{-2}\right)$, and crosslinking time ( $\left.\mathrm{min}\right)$ levels are equal to $5 \%$, $10 \%$, and $15 \% ; 100 \mathrm{~g} \mathrm{~m}^{-2}, 150 \mathrm{~g} \mathrm{~m}^{-2}$, and $200 \mathrm{~g} \mathrm{~m}^{-2}$; and $2 \mathrm{~min}, 4 \mathrm{~min}$, and $6 \mathrm{~min}$, respectively. Coated samples were dried for 5 minutes at $100^{\circ} \mathrm{C}$ and crosslinked at $160^{\circ} \mathrm{C}$. The variation margin of the fluorocarbon resin percentage was chosen based on the product datasheet specifications and calculated as a function of the textile sample mass. Acrylic paste and reticulation time levels were fixed after preliminary testing.

\subsection{Coating Add-On (\%) and Thickness ( $\mathrm{mm}$ ) Measurement.} Textile coating consists of applying a semiliquid polymeric formulation to one of fabric faces or both. The substrate is then dried and reticulated [10]. To determine the amount of coating that is added to the textile fabric, the coating add-on percentage $\left(C_{\text {add-on }}\right)$ is calculated by using the following equation $[8,11]$ :

$$
C_{\text {add-on }}(\%)=\frac{m_{a t}-m_{b t}}{m_{b t}} \times 100,
$$

where $m_{b t}$ and $m_{a t}$ are the masses of the studied samples, expressed in gram $(\mathrm{g})$, before and after the coating treatment, respectively.

Thickness of the applied coating is of a major importance when evaluating the coated fabric performances and validating its suitability for the intended end-use [12]. In the present research, the thickness of the cotton-PES blended woven fabric was analyzed before and after the coating treatment. The overall measurements were performed by using a thickness gauge type 310 8A Mesdan Lab from Sodemat, Troyes. Tests were done according to ISO 5084 standard [13].
TABLE 1: Used coating screen characteristics.

\begin{tabular}{lc}
\hline Characteristics & Values \\
\hline External screen length & $33 \mathrm{~cm}$ \\
External screen width & $31 \mathrm{~cm}$ \\
Internal screen length & $28 \mathrm{~cm}$ \\
Internal screen width & $26 \mathrm{~cm}$ \\
Mesh porosity & 26 pores cm \\
Hole size & $122 \times 109 \mu \mathrm{m}$ \\
\hline
\end{tabular}

2.4. Infrared Spectroscopy Analysis. To determine the functional groups in the textile surface, infrared spectroscopy analysis was performed by using an FT-IR spectrometer from PerkinElmer. Besides, the uncoated and coated samples were analyzed. Measurement frequency scale $\left(\mathrm{cm}^{-1}\right)$ was fixed from 4000 to $400 \mathrm{~cm}^{-1}$. Each infrared spectrum was the average of three scans. An air background spectrum was run before analyzing samples.

2.5. Optical Microscopy Analysis. The uncoated and the coated samples were observed under an optical Leica StereoMicroscope type M50 (Leica Microsystems, Germany). The used microscope comprises five focus lenses enabling an onscreen magnification ranging from $20 \mathrm{X}$ to $128 \mathrm{X}$. To have images with a high precision focusing system, a Leica Biological Microscope type DM 50 (Leica Microsystems, Germany) was also employed. This device was supplied with four focus lenses allowing an on-screen magnification ranging from $128 \mathrm{X}$ to $1280 \mathrm{X}$.

2.6. Air Permeability Measurement $\left(\mathrm{L} \mathrm{m}^{-2} \mathrm{~s}^{-1}\right)$. Protective criteria are of major interest for producing medical gowns. Still, the ability of the gown to confer comfort to the wearer is also an important factor to be analyzed. Since air permeability is related to the garment thermal comfort, this response was measured by using the TEXTEST FX3300 Tester. Air permeability was evaluated for both fabric surfaces before and after the coating treatment. Tests were done according to the ISO 9237 standard [14].

2.7. Evaluation of Surface Wetting (Spray Test). To evaluate the resistance of the woven fabric to surface wetting, the spray test was used. Tests were done according to the ISO 4920 standard [15]. Square samples with $1800 \mathrm{~mm}$ sides were mounted on the ring of a spray rating tester $\left(45^{\circ}, 150 \mathrm{~mm}\right)$. Tested samples were subjected to a spray nozzle and a volume of $250 \mathrm{~mL}$ of distilled water was used to water their surfaces. By referring to standard spray test ratings photography chart $[16,17]$, water repellency levels of the tested samples were determined.

2.8. Evaluation of Woven Fabric Stiffness. The stiffness was measured for the uncoated and coated samples with a Cantilever test apparatus. Tests were done according to the ASTDM D 1388-96 standard [18]. Samples were tested according to fabric warp and weft directions. The bending 
length (c) was first calculated by using the following equation [18]:

$$
c(\mathrm{~cm})=\frac{o}{2}
$$

where $o$ is the length of overhang $(\mathrm{cm})$.

The flexural rigidity $(G)$ was then deduced by using the following equation [18]:

$$
G(\mathrm{mg} \cdot \mathrm{cm})=W \times c^{3}
$$

where $W\left(\mathrm{mg} \cdot \mathrm{cm}^{-2}\right)$ is the fabric mass.

\section{Results and Discussion}

3.1. Coating Add-On (\%) and Thickness ( $\mathrm{mm}$ ) Analysis. Coating add-on values were determined for the coated samples. The obtained values are recapitulated in Table 2. For the uncoated cotton-PES blended fabric, the mass value was equal to $180 \pm 0.001 \mathrm{~g} \mathrm{~m}^{-2}$. After applying the coating paste, a significant increase in sample masses was noticed. As shown in Figure 1, the obtained $C_{\text {add-on }}$ values ranged from $22 \pm 0.017 \%$ to $47 \pm 0.01 \%$. It is notable that the highest coating add-on value was obtained with $15 \%$ of fluorocarbon resin, $200 \mathrm{~g} \mathrm{~m}^{-2}$ of acrylic paste, and a crosslinking time equal to $4 \mathrm{~min}$.

The woven fabric thickness was measured before and after the coating treatment. Before treating the cotton-PES blended woven (pristine fabric), its thickness was equal to $0.250 \pm 0.007 \mathrm{~mm}$. The evolution of thickness values after the coating treatment for the cotton-PES blended woven samples is shown in Figure 2.

After the coating treatment, the thickness of the woven fabric decreased. This can be explained by the fact that the coating paste reduced the fabric surface pilling which has decreased its thickness. In fact, the applied coating was introduced into fabric voids and fulfilled interfibers and interfilaments space. This explains the decrease in the thickness value after the coating treatment. The thickness mean value for all the treated samples was equal to $0.209 \mathrm{~mm}$ with a standard deviation value equal to $0.010 \mathrm{~mm}$. So, it can be deduced that varying input parameters in the studied intervals of interest does not affect thickness response.

\subsection{Infrared Spectroscopy Analysis. Infrared spectroscopy} was used to detect functional groups in both uncoated and coated samples. Based on the obtained spectrums, changes that have occurred in the woven structure surface after applying the coating paste were also analyzed. The FT-IR spectra of the uncoated woven fabric are shown in Figure 3. The untreated sample is a cotton-polyester blend. Peaks in the obtained FT-IR spectrum are the results of vibration modes of both functional groups in cotton and polyester.

The vibrational mode between 3500 and $2800 \mathrm{~cm}^{-1}$ is the result of $\mathrm{O}-\mathrm{H}$ and $\mathrm{C}-\mathrm{H}$ stretching $[19,20]$. From the spectrum represented in Figure 3, peaks at 3336 and $2914 \mathrm{~cm}^{-1}$ correspond to the stretching vibration of $\mathrm{O}-\mathrm{H}$ and $\mathrm{C}-\mathrm{H}$ functional groups of the cotton fiber, respectively. Otherwise, vibration at 1505 is attributed to $\mathrm{O}-\mathrm{H}$ bending mode. The strong peak at $1017 \mathrm{~cm}^{-1}$ is relative to the stretching mode of $\mathrm{C}-\mathrm{O}$ functional group present in the cotton fiber chemical structure.

The chemical structure of polyester is mainly composed of alcohol, ester, anhydride, and aromatic ring [21]. Vibrations of $\mathrm{C}=\mathrm{O}$ and $\mathrm{C}-\mathrm{O}$ stretching modes are detected at 1713 and $1017 \mathrm{~cm}^{-1}$, respectively. Moreover, the aromatic ring peak of the polyester compound is at $1408 \mathrm{~cm}^{-1}$. The carboxylic ester peak was noticed at $1240 \mathrm{~cm}^{-1}$. The vibration mode of aromatic ring hydrogen groups is detected at $871 \mathrm{~cm}^{-1}$.

Acrylic resins are the result of acrylate and methacrylate monomers polymerization [22, 23]. In this research, the used coating paste is mainly composed of acrylic and fluorocarbon resins. By referring to the FT-IR spectrum of the coated sample represented in Figure 4, it can be noticed that the chemical surface nature was modified after the coating treatment. The strong peak at $2923 \mathrm{~cm}^{-1}$ is relative to the $\mathrm{C}-\mathrm{H}$ stretching mode. Vibrations of $\mathrm{C}=\mathrm{O}$ and $\mathrm{C}-\mathrm{O}$ stretching modes are detected at 1704 and $1066 \mathrm{~cm}^{-1}$, respectively. The peak at $1242 \mathrm{~cm}^{-1}$ corresponds to C-F stretching mode.

3.3. Optical Microscopic Images Analysis. In this research, uncoated and coated fabrics were analyzed using Leica microscopes types M50 and DM closedup 50. Based on the image obtained with the microscope type Leica M50 and an on-screen magnification equal to $51 \mathrm{X}$, fabric characteristics were determined (Figure 5). The used fabric is a plain weave woven structure. Its porosity is equal to 20 pores $\mathrm{cm}^{-2}$. Length and width of rectangular shape pores are equal to 135 and $70 \mu \mathrm{m}$, respectively.

The assembled yarn structure that is forming the investigated woven fabric is shown in Figure 6. It is a cottonpolyester fibers blend in three different magnifications.

It is well known that textiles are considered as hierarchical porous structures. After the coating treatment, the textile surface morphology was modified. Based on Figure 7 , the coating paste full-field interfiber and interyarn spaces can be noticedi. As a result, pores distribution, sizes, and shapes were modified. Besides, a more compact structure with blocked yarns was obtained. By examining the treated sample morphology, it can be concluded that the applied coating has not only modified the fabric surface chemistry but also its morphology and its topology.

3.4. Study of the Air Permeability $\left(\mathrm{L} \mathrm{m}^{-2} \mathrm{~s}^{-1}\right)$. The air permeability of the uncoated and the coated cotton-PES woven fabric samples was measured. Both sides of tested samples were subjected to an air flow by the aim of a TEXTEST FX 3300 device. According to findings, the air permeability values relative to the uncoated fabric inner and outer sides were equal to $393.2 \pm 13.828 \mathrm{~L} \mathrm{~m}^{-2} \mathrm{~s}^{-1}$ and $393.6 \pm 11.480 \mathrm{~L} \mathrm{~m}^{-2} \mathrm{~s}^{-1}$, respectively. Indeed, all the air permeability values for the different tested samples are summarized in Table 3. Referring to these findings, it can be concluded that the coating treatment has decreased significantly the air permeability of the cotton-PES blended woven fabric. 
TABLE 2: $C_{\text {add-on }}(\%)$ and thickness $(\mathrm{mm})$ values of the coated woven fabric samples.

\begin{tabular}{|c|c|c|c|c|c|}
\hline \multirow{2}{*}{ Exp. No. } & \multicolumn{3}{|c|}{ Factors } & \multirow{2}{*}{$C_{\text {add-on }}(\%)$} & \multirow{2}{*}{ Thickness (mm) } \\
\hline & Fluorocarbon resin (\%) & Acrylic resin $\left(\mathrm{g} \mathrm{m}^{-2}\right)$ & Crosslinking time (min) & & \\
\hline 1 & 5 & 100 & 4 & $22 \pm 0.017$ & $0.250 \pm 0.005$ \\
\hline 2 & 15 & 100 & 4 & $27 \pm 0.011$ & $0.196 \pm 0.005$ \\
\hline 3 & 5 & 200 & 4 & $44 \pm 0.023$ & $0.204 \pm 0.005$ \\
\hline 4 & 15 & 200 & 4 & $47 \pm 0.010$ & $0.196 \pm 0.008$ \\
\hline 5 & 5 & 150 & 2 & $35 \pm 0.023$ & $0.222 \pm 0.010$ \\
\hline 6 & 15 & 150 & 2 & $30 \pm 0.024$ & $0.230 \pm 0.009$ \\
\hline 7 & 5 & 150 & 6 & $30 \pm 0.018$ & $0.216 \pm 0.005$ \\
\hline 8 & 15 & 150 & 6 & $31 \pm 0.005$ & $0.204 \pm 0.008$ \\
\hline 9 & 10 & 100 & 2 & $25 \pm 0.004$ & $0.202 \pm 0.009$ \\
\hline 10 & 10 & 200 & 2 & $39 \pm 0.013$ & $0.206 \pm 0.007$ \\
\hline 11 & 10 & 100 & 6 & $26 \pm 0.007$ & $0.220 \pm 0.008$ \\
\hline 12 & 10 & 200 & 6 & $43 \pm 0.031$ & $0.198 \pm 0.008$ \\
\hline $13^{\mathrm{a}}$ & 10 & 150 & 4 & $36 \pm 0.005$ & $0.206 \pm 0.009$ \\
\hline $14^{\mathrm{a}}$ & 10 & 150 & 4 & $33 \pm 0.009$ & $0.214 \pm 0.009$ \\
\hline $15^{\mathrm{a}}$ & 10 & 150 & 4 & $37 \pm 0.002$ & $0.208 \pm 0.008$ \\
\hline
\end{tabular}

"a" indicates the design central point.

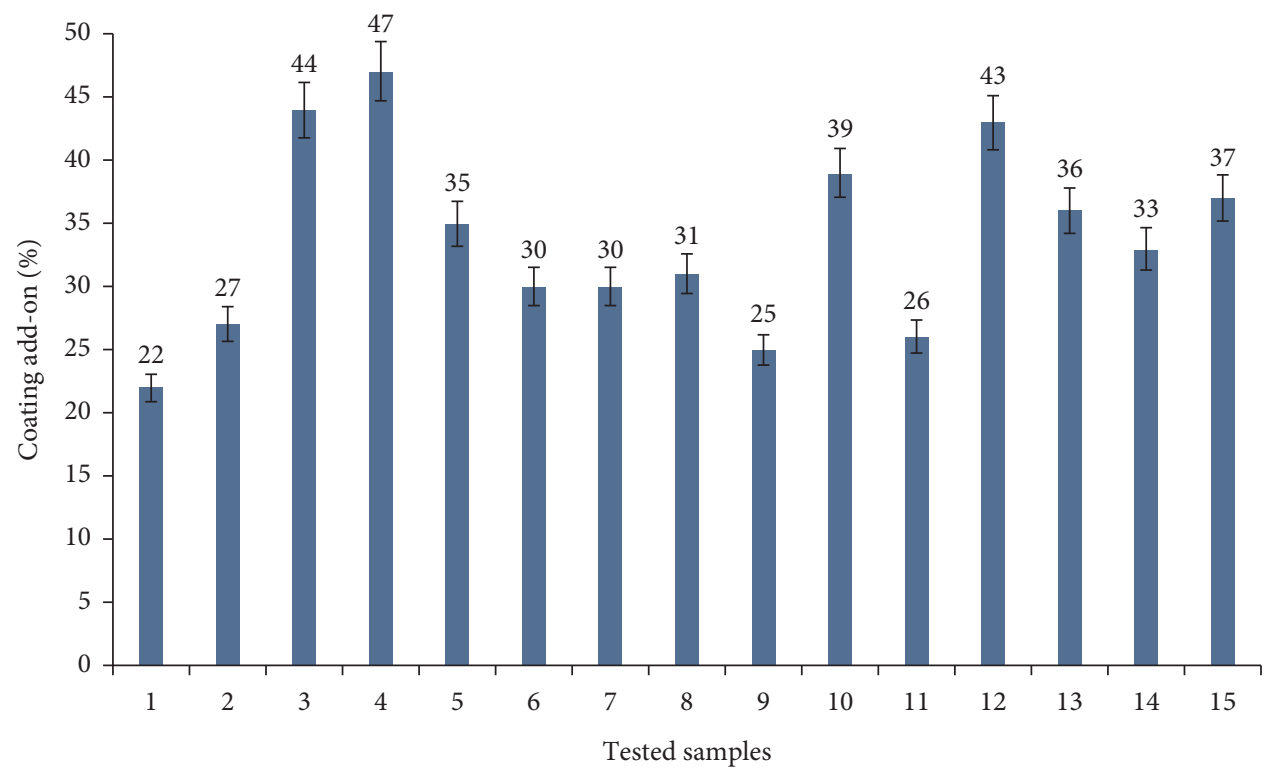

FIGURE 1: Evolution of the $C_{\text {add-on }}(\%)$ values for the coated woven fabric samples.

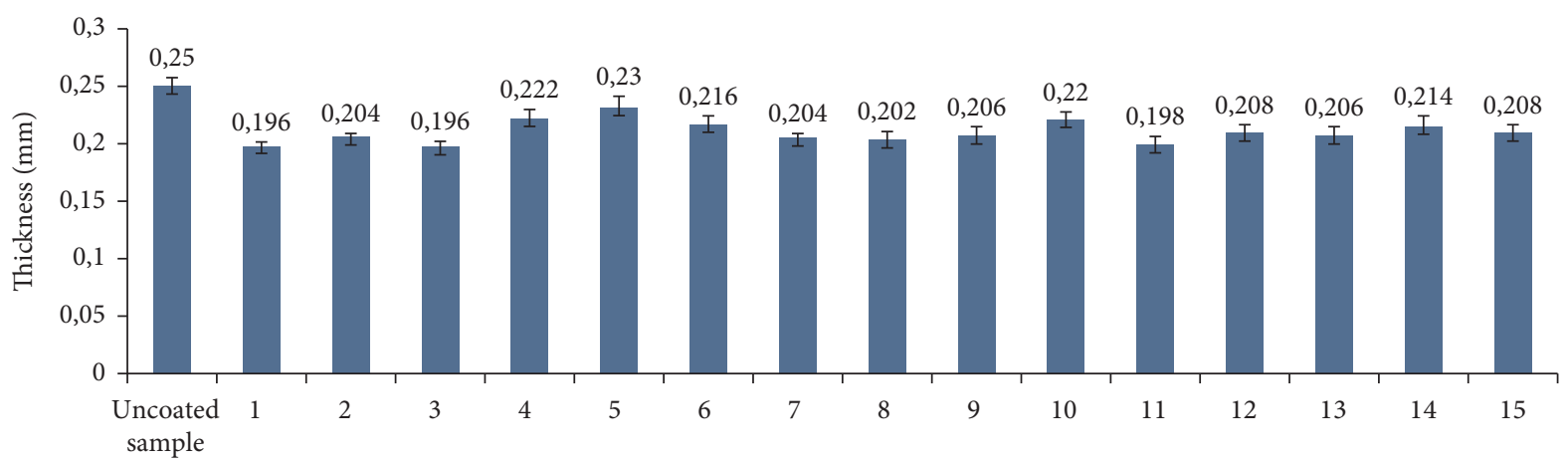

Tested samples

FIGURE 2: Evolution of thickness values for the uncoated and coated woven specimens. 


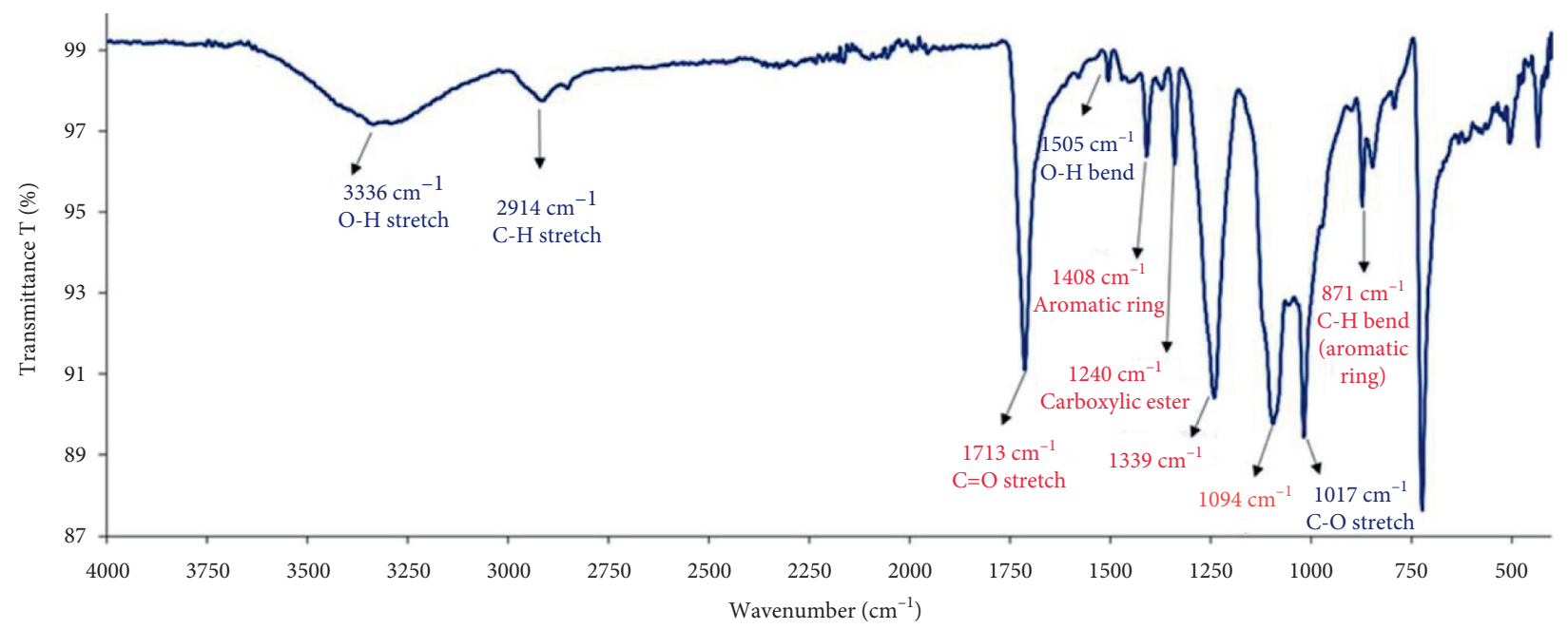

FIgURE 3: Absorption peaks in FT-IR spectra of the uncoated woven fabric.

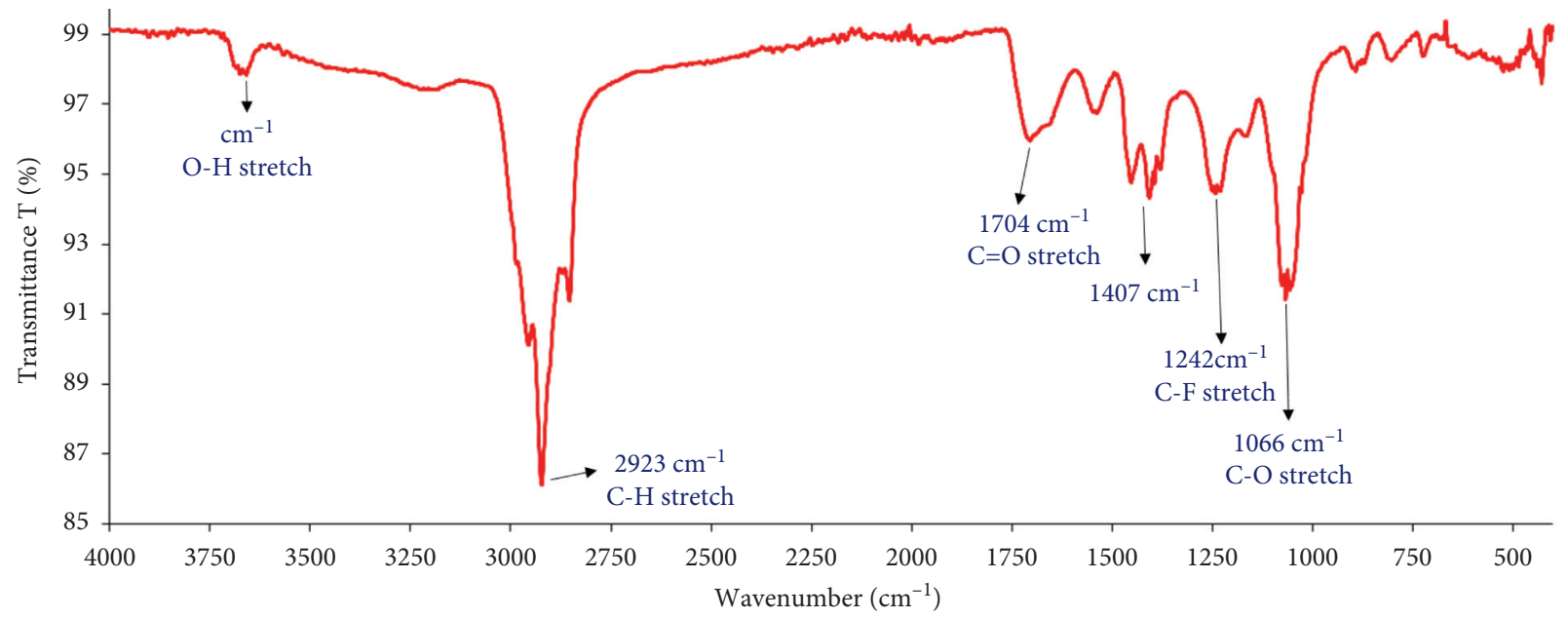

FIGURE 4: Absorption peaks in FT-IR spectra of the coated woven fabric (fluorocarbon resin: $15 \%$, acrylic paste: $150 \mathrm{~g} \mathrm{~m}^{-2}$, and reticulation time: $6 \mathrm{~min}$ ).

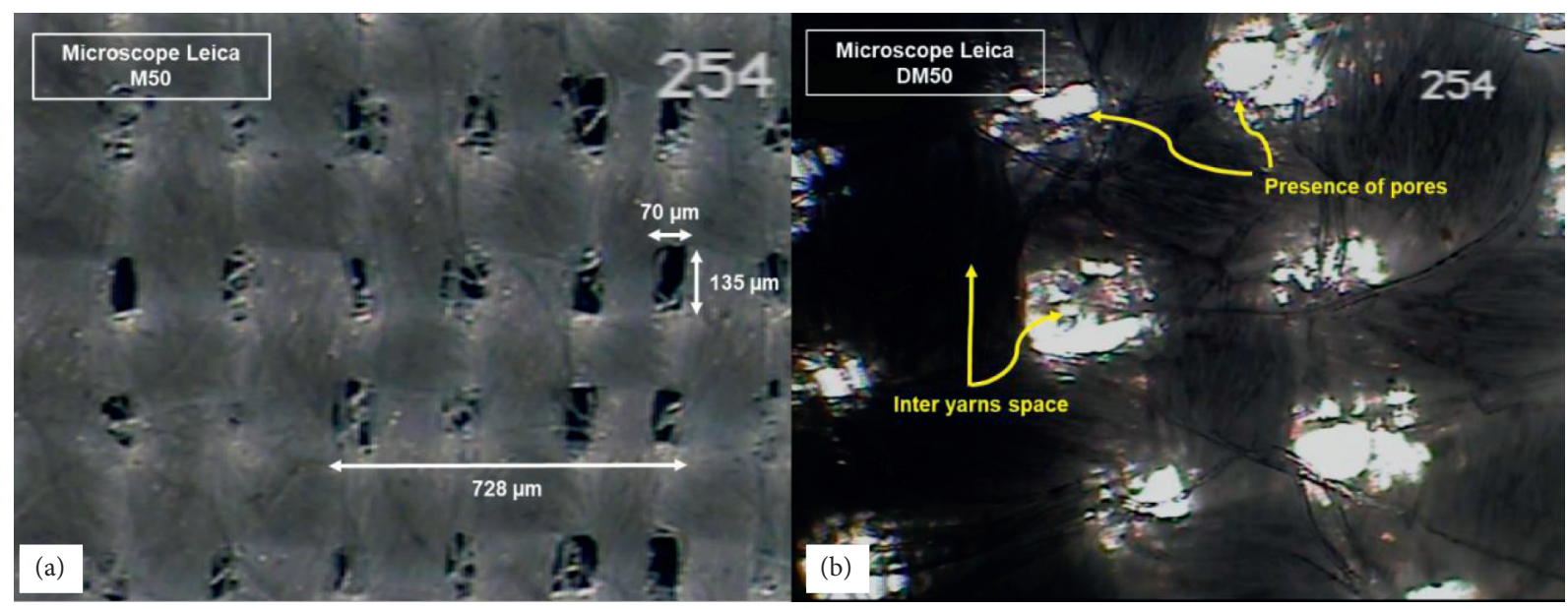

FIGURE 5: Surface morphology of the uncoated cotton-PES blended woven fabric. (a) 51X on-screen magnification and (b) $128 \mathrm{X}$ on-screen magnification. 

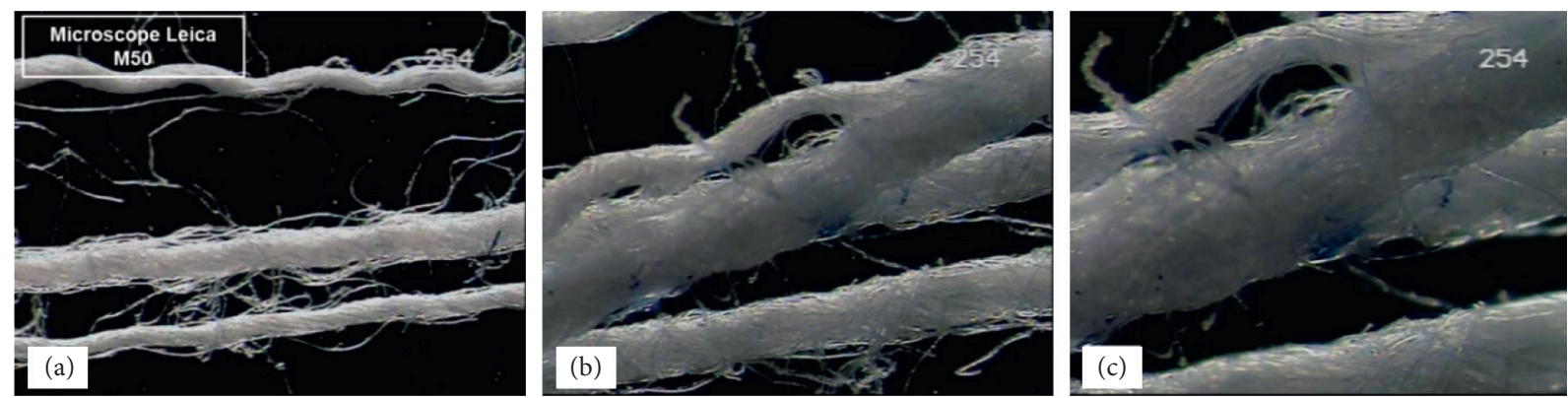

FIgURE 6: Images of the woven fabric cotton-PES assembled yarn. (a) 51X on-screen magnification. (b) 80X on-screen magnification. (c) $128 \mathrm{X}$ on-screen magnification.

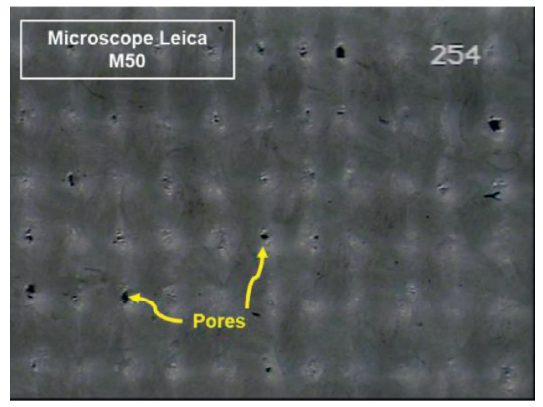

(a)

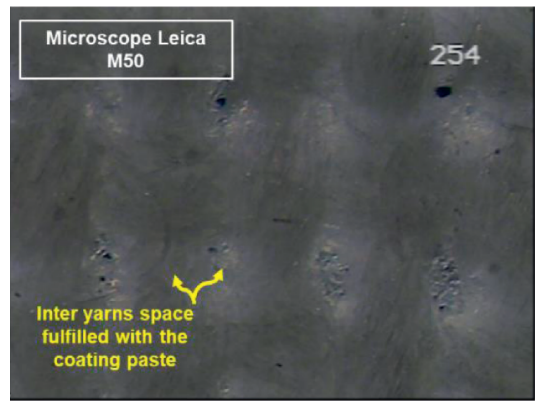

(b)

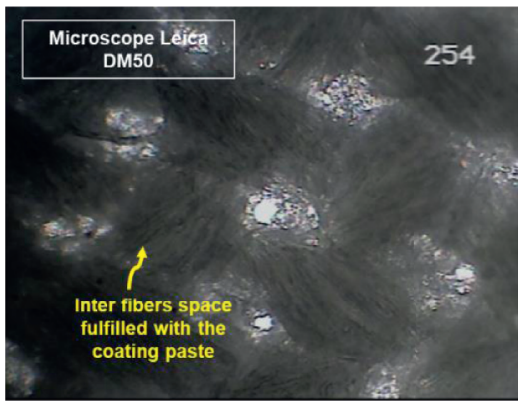

(c)

FIGURE 7: Surface morphology of the coated cotton-PES woven fabric (fluorocarbon resin: 15\%, acrylic paste: $20 \mathrm{~g} \mathrm{~m}^{-2}$, and crosslinking time: $4 \mathrm{~min}$ ). (a) $51 \mathrm{X}$ on-screen magnification. (b) $128 \mathrm{X}$ on-screen magnification. (c) 128X on-screen magnification.

TABLE 3: Air permeability values $\left(\mathrm{L} \mathrm{m}^{-2} \mathrm{~s}^{-1}\right)$ of the coated inner and outer faces of the studied samples.

\begin{tabular}{lcccc}
\hline \multicolumn{5}{c}{ Air permeability $\left(\mathrm{L} \mathrm{m}^{-2} \mathrm{~s}^{-1}\right)$} \\
Exp. No. & $\begin{array}{c}\text { Inner } \\
\text { face }\end{array}$ & $\begin{array}{c}\text { Standard } \\
\text { deviation }\end{array}$ & $\begin{array}{c}\text { Outer } \\
\text { face }\end{array}$ & Standard deviation \\
\hline 1 & 92.380 & 1.092 & 91.502 & 1.031 \\
2 & 102.600 & 1.817 & 103.400 & 1.517 \\
3 & 33.380 & 0.095 & 33.020 & 0.597 \\
4 & 39.240 & 2.445 & 39.200 & 3.128 \\
5 & 81.200 & 5.841 & 80.340 & 2.852 \\
6 & 86.140 & 1.464 & 84.400 & 2.402 \\
7 & 47.680 & 1.357 & 46.500 & 2.557 \\
8 & 46.700 & 3.678 & 44.040 & 2.040 \\
9 & 118.000 & 5.000 & 116.600 & 2.074 \\
10 & 37.900 & 1.409 & 36.140 & 0.811 \\
11 & 96.120 & 1.219 & 98.720 & 4.419 \\
12 & 24.580 & 1.952 & 24.260 & 0.713 \\
$13^{\mathrm{a}}$ & 41.320 & 3.980 & 42.200 & 2.699 \\
$14^{\mathrm{a}}$ & 41.020 & 3.478 & 40.400 & 1.458 \\
$15^{\mathrm{a}}$ & 40.420 & 1.464 & 40.800 & 2.414 \\
\hline
\end{tabular}

"a" indicates the design central point.

To analyze the effect of each studied parameter on the air permeability property, the Minitab 14 software was used. Indeed, the main effects plot for this response (Figure 8(a)) and statistical analyses were performed. Based on obtained results, it was found that the acrylic paste quantity has the most significant effect on the studied response with a nonparallel main effect plot line and $p$ values equal to 0.01 and to $0.005(<0.05)$ for the fabric inner and outer sides, respectively. The acrylic paste is considered as a plug that fills yarn-to-yarn and fiber-to-fiber spaces which decreased the woven structure porosity. Consequently, the air permeability value of the tested fabric was reduced notably. On the other side, the effect of the fluorocarbon resin quantity on the air permeability of both fabric faces was considered insignificant with main effects plotted line almost parallel to the $X$ axis and $p$ values equal to 0.273 and 0.159 , respectively, for the fabric inner and outer faces. The high significance of the acrylic resin quantity and the nonsignificance of the fluorocarbon resin quantity can also be observed in Figure 8(b), where the air permeability is represented as function of acrylic paste ( $X$-axis) and fluorocarbon resin ( $Y$-axis) quantities. The variation in the acrylic resin quantity generated a plane that is deviated by almost $45^{\circ}$ from $(X, Y)$ plan.

Two models were set to predict accurately the air permeability of both coated fabric sides in the experimental design of interest (equation (3)). The coefficient of regression, $R^{2}$, values for air permeability set models were equal to 96.8 for fabric inner side and $97.6 \%$ for the fabric outer one. Thus, based on their accuracy (close to $100 \%$ ), it can be concluded that fitted determined values are close to those observed.

3.5. Study of the Surface Wetting. To evaluate surface wetting of the cotton-PES blended woven fabric, the spray test method was used. Moreover, the uncoated and coated samples were tested. The untreated woven fabric showed a complete wetting by distilled water. Obtained results for the 


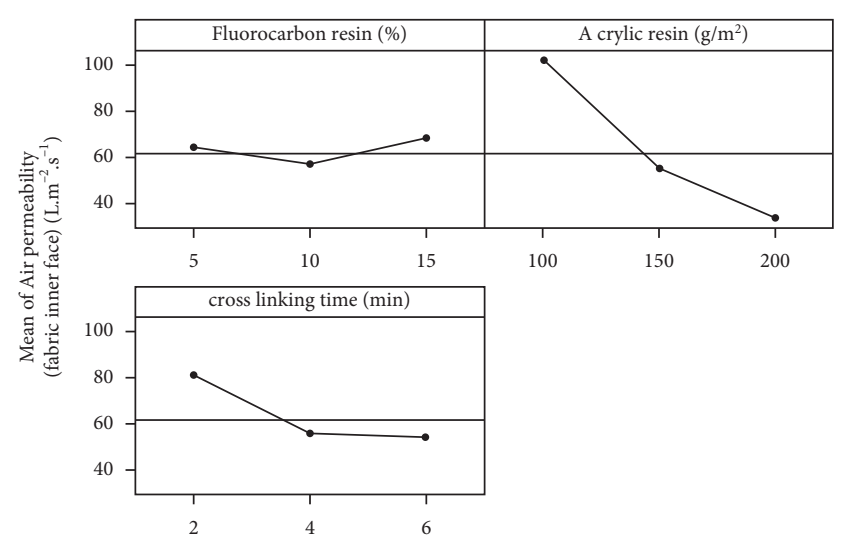

(a)

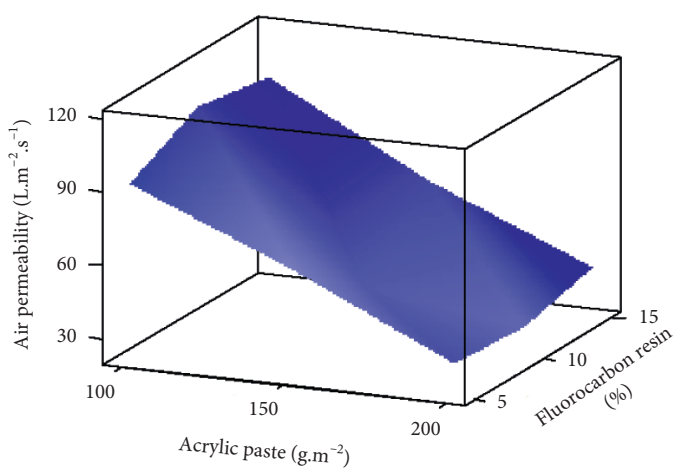

(b)

FIGURE 8: Air permeability behaviors for the coated inner face of woven fabric. (a) Main effect evolutions. (b) Surface plot.

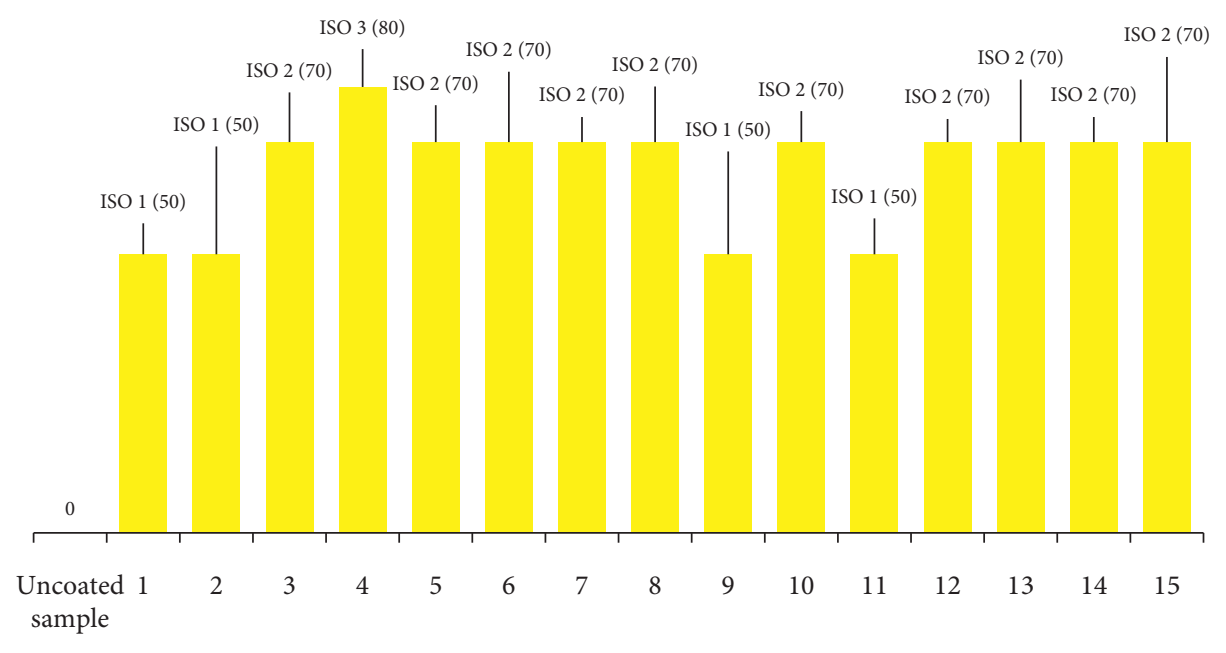

Tested samples

FIGURE 9: Uncoated and coated sample resistances in terms of surface wetting (spray test).

different tested samples are shown in Figure 9. After the coating treatment, an enhancement in water repellent property of the woven fabric was noticed.

To analyze the effect of each input parameter on the studied response, the main effects plot and statistical analysis of water repellency relative to the coated samples were discussed thanks to the Minitab software.

Undoubtedly, textile surface wetting depends on fabric characteristics such as warp and weft end counts, porosity, and yarn twist. In fact, the textile surface chemistry also affects its hydrophilic/hydrophobic property. By comparing overall main effects plots for water repellency of the coated samples (Figure 10), the acrylic resin effect on the fabric water repellency is the highest one. This finding was improved by the acrylic resin quantity $p$ value which was equal to $0.054(\approx 0.05)$. The hydrophobic property of the acrylic resin and its capacity to fullfil interfilaments and interfibers space explain the important increase in the water repellent property of the coated samples.

Plotted lines relative to fluorocarbon resin (\%) and reticulation time (min) were almost parallel to the $X$-axis meaning that the effects of these two parameters on the water repellency response are insignificant. Therefore, obtained $p$ values for fluorocarbon resin and crosslinking time were equal to 0.942 and 0.481 , respectively. Indeed, they are higher than 0.05 . It is true that fluorocarbons are known for having the lowest surface energy; however, varying this product quantity in the studied interval of interest has not influenced significantly the water repellent property.

3.6. Evaluating the Flexural Rigidity $(\mathrm{mg} \mathrm{cm})$. Similarly, the bending length $(\mathrm{cm})$ and the flexural rigidity $(\mathrm{mg} \mathrm{cm})$ of the woven cotton-PES blended fabric were evaluated for uncoated and coated woven samples. Before applying the coating paste, the bending lengths of the woven structure were equal to $2.15 \pm 0.071 \mathrm{~cm}$ in the warp direction and to $2 \pm 0.141 \mathrm{~cm}$ in the weft one. The flexural rigidity was calculated using equations (2) and (3). Indeed, it was equal to 179.258 and $145.142 \mathrm{mg} \mathrm{cm}$ for warp and weft directions, respectively.

After the coating treatment, the bending length $(\mathrm{cm})$ (Figure 11) and flexural rigidity $(\mathrm{mg} \mathrm{cm})$ (Figure 12) values 


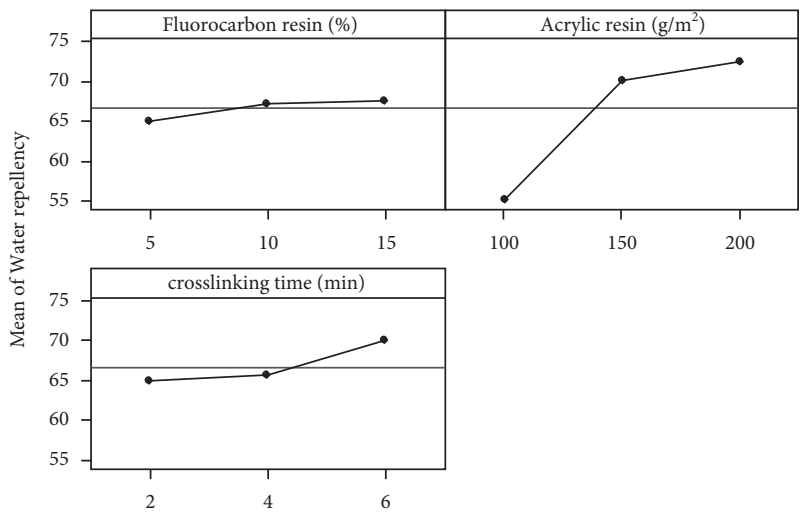

FIgURE 10: Main effects plot (data means) for water repellency of the coated samples.

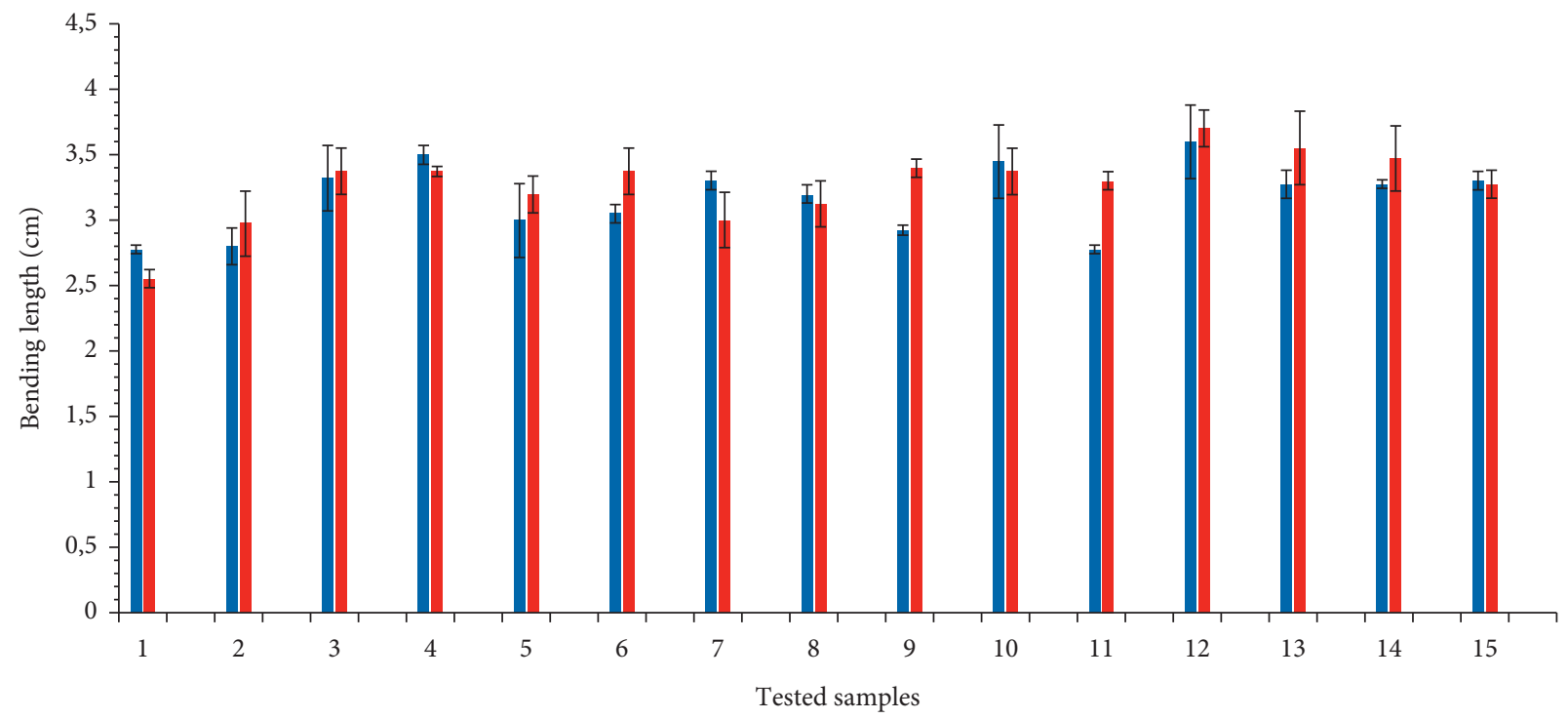

- Warp direction

- Weft direction

FIGURE 11: Bending length $(\mathrm{cm})$ for coated samples measured according to warp and weft directions.

increased significantly. The highest bending lengths were equal to $3.6 \pm 0.283 \mathrm{~cm}$ and $3.7 \pm 0.141 \mathrm{~cm}$ for warp and weft directions, respectively. These bending length values correspond to flexural rigidities equal to 1208.592 and $1302.94 \mathrm{mg} \mathrm{cm}$ for warp and weft directions, respectively. Hence, it can be concluded that the coating treatment rigidified the woven fabric structure.

Statistical analysis was conducted using Minitab 14 software. Based on findings, $p$ values were equal to 0.113 , 0.572 , and 0.837 (>0.05), respectively, for fluorocarbon resin $(\%)$, acrylic paste $\left(\mathrm{g} \mathrm{m}^{-2}\right)$, and crosslinking time (min). Therefore, according to the statistical results, the effects of the three-input parameters on the warp flexural rigidity were judged to be insignificant. The statistical analysis of flexural rigidity values according to weft direction showed that the fluorocarbon resin has the most significant effect with a $p$ value equal to 0.01 .

Contour plot for the coated cotton-PES blended samples is shown in Figure 13. This graph can be used to set input parameters in order to obtain a specified flexural rigidity behavior. For example, to have a flexural rigidity higher than $1200 \mathrm{mg} \mathrm{cm}$ with an acrylic resin quantity 


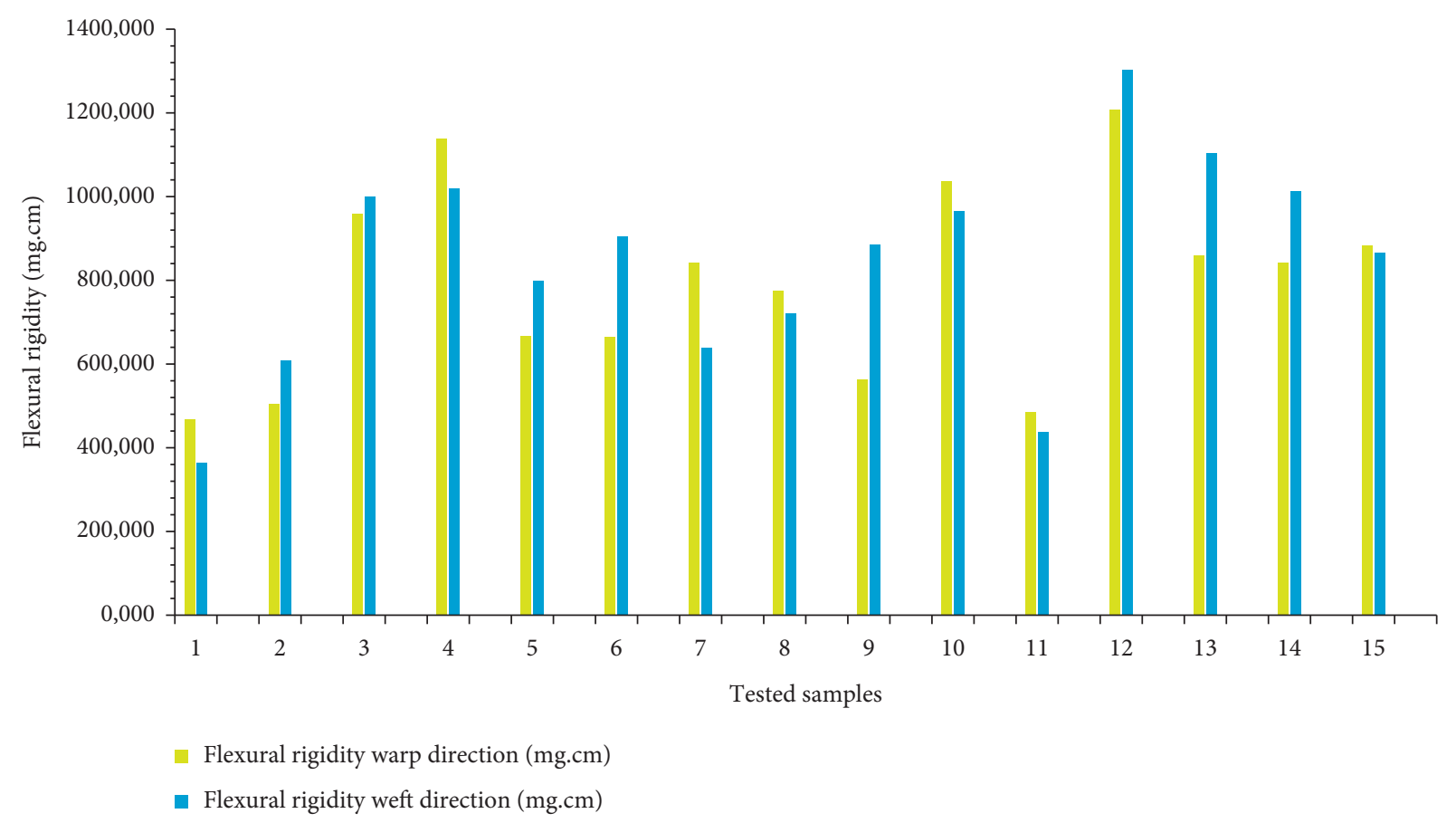

FIgURE 12: Flexural rigidity behavior for coated samples measured according to warp and weft directions.

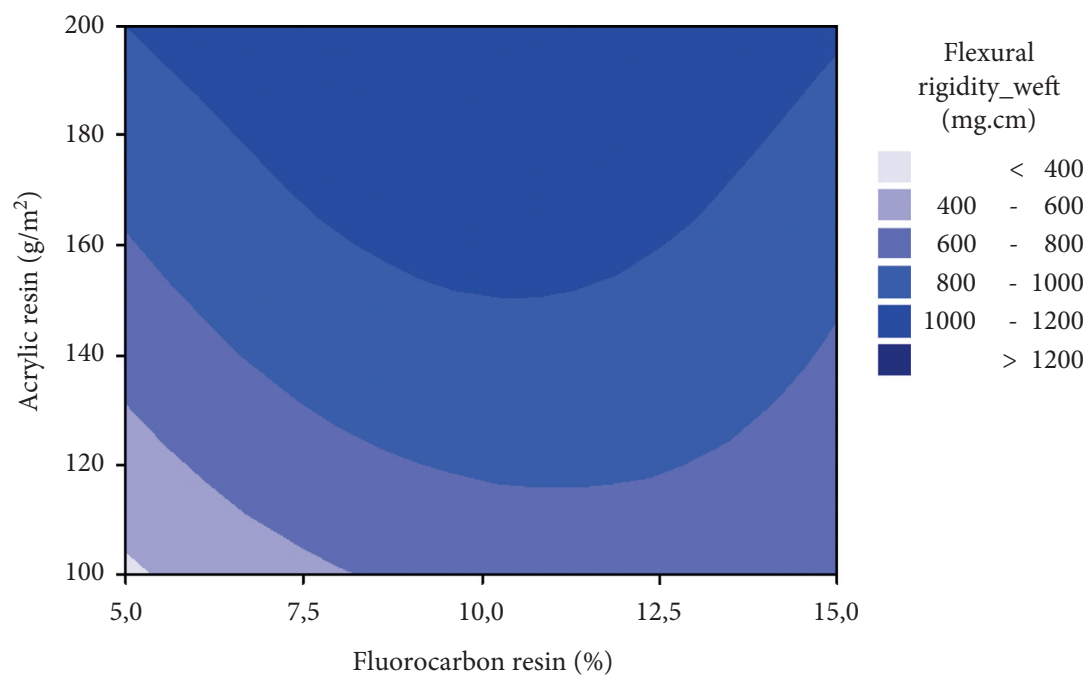

FIGURE 13: Contour plot for the weft flexural rigidity of the coated cotton-PES blended fabric.

equal to $163.5 \mathrm{~g} \mathrm{~m}^{-2}$, fluorocarbon resin quantity must be ranged from 8.12 to $13.16 \%$.

\section{Conclusion}

The aim of this research was to develop a coated cotton-PES woven fabric that can be used for producing protective gowns. For this purpose, a coating comprising fluorocarbon and acrylic resins was applied to the fabric with the screen coating process. The quantities of the two used resins and the reticulation time were varied according to three levels by using the Box-Behnken experimental design. For uncoated and coated samples, thickness (mm), coating add-on (\%), infrared spectroscopy analysis, optical microscopy analysis, air permeability $\left(\mathrm{L} \mathrm{m}^{-2} \mathrm{~s}^{-1}\right)$, surface wetting, and fabric stiffness $\left(\mathrm{mg} \mathrm{cm}^{-1}\right)$ were evaluated.

High and low coating add-on values were equal to $22 \pm 0.017 \%$ and $47 \pm 0.01 \%$, respectively. Thickness value $(\mathrm{mm})$ was almost the same for all treated samples (a mean thickness equal to $0.209 \pm 0.01 \mathrm{~mm}$ ). A significant decrease in air permeability was noticed after applying the polymeric coating to the woven structure. On the other hand, an increase in surface hydrophobicity was remarked. When evaluating the flexural rigidity, it was obvious that the coating treatment rigidified the woven structure. Moreover, to improve the effectiveness of the developed models, the 
coefficient of regression $R^{2}$ and statistical $p$ values are discussed. Indeed, four multiregressive models were evaluated to predict accurately the air permeability property of both fabric sides $\left(\mathrm{L} \mathrm{m}^{-2} \mathrm{~s}^{-1}\right)$, water repellency, and flexural rigidity $\left(\mathrm{mg} \mathrm{cm}^{-1}\right)$. Based on the accurate findings, it can be concluded that these models are useful and fruitful for prediction in the experimental design of interest.

\section{Data Availability}

The data used to support the findings of this study are included within the article.

\section{Conflicts of Interest}

The authors declare that they have no conflicts of interest.

\section{References}

[1] M. A. Chowdhury, M. B. A. Shuvho, M. A. Shahid et al., "Prospect of biobased antiviral face mask to limit the coronavirus outbreak," Environmental Research, vol. 192, Article ID 110294, 2020.

[2] A. Kumar, K. Sharma, and A. Rai Dixit, "Role of graphene in biosensor and protective textile against viruses," Medical Hypotheses, vol. 144, Article ID 110253, 2020.

[3] M. Mcquerry, E. Easter, and A. Cao, "Disposable versus reusable medical gowns: a performance comparison," American Journal of Infection Control, vol. 49, no. 5, pp. 563-570, 2021.

[4] H. K. Kaynak and H. I. Çelik, "Investigation of the permeability properties of commercially available reusable and disposable surgical gowns," in Proceedings of the 8th International Istanbul Conference-Evolution Technical Textile (ETT2018), pp. 1-7, Istanbul, Turkey, 2018.

[5] F. A. Drews, D. Mulvey, K. Stratford, M. H. Samore, and J. Mayer, "Evaluation of a redesigned personal protective equipment gown," Clinical Infectious Diseases, vol. 69, pp. S199-S205, 2019.

[6] F. S. Kilinc, "A review of isolation gowns in healthcare: fabric and gown properties," Journal of Engineered Fibers and Fabrics, vol. 10, no. 3, pp. 180-190, 2015.

[7] B. K. Behera and H. Arora, "Surgical gown: a critical review," Journal of Industrial Textiles, vol. 38, no. 3, pp. 205-231, 2009.

[8] I. Ghezal, A. Moussa, I. Ben Marzoug, A. El-Achari, C. Campagne, and F. Sakli, "Development and surface state characterization of a spacer waterproof breathable fabric," Fibers and Polymers, vol. 21, no. 4, pp. 910-920, 2020.

[9] I. Ghezal, A. Moussa, I. B. Marzoug, A. El-Achari, C. Campagne, and F. Sakli, "Evaluating the mechanical properties of waterproof breathable fabric produced by a coating process," Clothing and Textiles Research Journal, vol. 37, no. 4, pp. 235-248, 2019.

[10] R. E. Meirowitz, "Coating processes and techniques for smart textiles," in Active Coatings For Smart Textiles, J. Hu, Ed., Woodhead Publishing, Sawston, Cambridge, UK, 2016.

[11] A. Ojstršek, N. Virant, D. Fox, L. Krishnan, and A. Cobley, "The efficacy of polymer coatings for the protection of electroless copper plated polyester fbaric," Polymers, vol. 12, no. 6, pp. 1277-1290, 2020.

[12] K. Singha, "A review on coating \& lamination in textiles: processes and applications," American Journal of Polymer Science, vol. 2, no. 3, pp. 39-49, 2012.
[13] ISO 5084-Determination of Thickness of Textiles and Textile Products, Department of Standards Malaysia, Cyberjaya, Malaysia, 1996.

[14] ISO 9237-Textiles-Determination of the Permeability of Fabrics to Air, ISO, Geneva, Switzerland, 1995.

[15] Canadian General Standards Board, ISO 4920-Determination of Resistance to Surface Wetting (Spray Test), Cambridge, Canada, Canadian General Standards Board, 2012.

[16] American Petroleum Institute, AATCC 22-Test Method for Water Repellency: Spray, American Petroleum Institute, Washington, DC, USA, 2012.

[17] BS 3424-26-Testing Coated Fabrics, Methods 29A, 29B, 29C and 29D, Methods for Determination of Resistance to Water Penetration and Surface Wetting, BSI Standards, London, UK, 1990.

[18] ASTM D1388-Standard Test Method for Stiffness of Fabrics, ASTM International, West Conshohocken, PA, USA, 2002.

[19] A. Allen, J. Foulk, and G. Gamble, "Preliminary Fouriertransform infrared spectroscopy analysis of cotton trash," Journal of Cotton Science, vol. 11, no. 1, pp. 68-74, 2007.

[20] D. Gaspar, S. N. Fernandes, A. G. de Oliveira et al., "Nanocrystalline cellulose applied simultaneously as the gate dielectric and the substrate in flexible field effect transistors," Nanotechnology, vol. 25, no. 9, pp. 1-11, 2014.

[21] S. S. Bhattacharya and S. B. Chaudhari, "Study on structural, mechanical and functional properties of polyester silica nanocomposite fabric," International Journal of Pure and Applied Sciences and Technology, vol. 21, no. 1, pp. 43-52, 2014.

[22] H. J. Fabris and W. G. Knauss, "Synthetic polymer adhesives," in Comprehensive Polymer Science and Supplements, Elsevier Science, Amsterdam, Netherlands, 1989.

[23] A. Bhatnagar, B. Arvidson, and W. Pataki, "Prepreg ballistic composites," in Lightweight Ballistic Composites Military And Law-Enforcement Applications, A. Bhatnagar, Ed., Woodhead Publishing, Sawston, Cambridge, UK, 2006. 